\title{
FACTORS INFLUENCING THE COLLEGE CHOICE DECISIONS OF GRADUATE STUDENTS
}

\author{
Ruth E. Kallio
}

This paper examines the relative influence of factors affecting the college choice decisions of graduate students. It is based on a 1986 survey of 2,834 admitted students at a major research university, to which 38 percent of the sample responded. Factor analysis of ratings of importance of 31 college characteristics yielded dimensions upon which student decisions are based. These results were used to build five scales of importance and preference, which were then tested with other variables in a regression model in which the dependent variable was the decision to enroll or not to enroll at the surveying institution. The following were found to influence decisions: residency status, quality and other academic environment characteristics, work-related concerns, spouse considerations, financial aid, and the campus social environment.

Since the early 1970s graduate education in the United States has been marked by shifting patterns of enrollments, student financial aid, and resource allocation due to the effects of a variety of larger social, economic, and political forces. One result of these conditions is intensified competition for students, a trend that will only increase over the decade of the 1990s if the projected decline in the number of baccalaureate degree recipients of 5 percent by the year 2000 (National Center for Education Statistics, 1989) actually occurs. These conditions have made it difficult for institutions to manage both the quantity and quality of their graduate student populations. They have also led to widespread concerns about projected shortages of doctorally trained personnel to meet the future needs of colleges and universities as well as other sectors of the labor market. Thus, there is a need for greater understanding of why students choose to attend graduate school and how they go about selecting one. The purpose of this paper is to examine the results of a study of the factors

Ruth E. Kallio, Associate Director, Office of Academic Planning and Analysis, University of Michigan, 520 E. Liberty, Ann Arbor, MI 48104-2210.

A paper presented at the Annual Forum of the Association for Institutional Research, New Orleans, May 29-June 1, 1994. 
influencing one pool of students in their decisions on which college or university to attend for graduate studies. This decision is usually referred to in the literature as the "college choice" decision even when it is being applied to graduate students rather than undergraduates.

\section{LITERATURE REVIEW}

This paper is based on two general hypotheses. First, that selecting a graduate school to attend is a multistage decision process affected by a variety of factors involving the student's characteristics, information gathering, college actions, and college/program characteristics. Second, the relative importance of some factors will differ for younger and older students due to the effects of life stage development, particularly as they relate to marriage, family and work considerations. These hypotheses are derived from two streams of literature describing the college choice process and adult development theory. Both the hypotheses and the literature are described more fully in Kallio (1993).

The notion that choosing a graduate school to attend is a multistage decision process is borrowed from the vast literature describing the college choice decisions of prospective undergraduate students. The publications that review and summarize this literature are too numerous to reference here. Two recent publications, however, that would provide an introduction to this topic include Hossler, Braxton, and Coopersmith (1989) and Paulsen (1990). These and other overviews of the literature describe the evolution of various conceptual models of the choice process beginning with Kotler's (1976) simple decision funnel and moving toward more complex and integrative models such as those developed by Litten, Sullivan, and Brodigan (1983) and Hossler and Gallagher (1987). In general these models suggest that the decision process consists of a number of stages or phases in which various individual and organizational factors interact to produce outcomes that influence the next stage or phase.

Although an extensive and growing body of literature on the college choice decisions of undergraduates exists, the same cannot be said for similar studies of graduate students. Virtually all reviews of the literature (e.g., Garet, ButlerNalin, and Bassage, 1982; Kuh et al., 1983; Malaney, 1988) document the scarcity of research on graduate students in general and on the decision processes leading to the choice of a graduate school in particular.

A handful of studies (e.g., Baird, 1976; Goldberg and Koenigsknecht, 1985; Malaney and Isaac, 1988; Ethington and Smart, 1986) examine issues surrounding the initial decision to attend graduate school. The findings of these studies suggest that students of greater academic achievement, higher socioeconomic background, and greater academic and social integration al their undergraduate institution are the most likely to pursue graduate studies. Men have 
also been found to be more likely than women to continue their studies, especially immediately after completing their baccalaureate degrees.

Other studies have focused on the reasons why students pursue graduate education. For example, Malaney (1987a) cites as common reasons: the desire to learn more about a specialty, personal satisfaction, improved job prospects, and an advanced degree needed for advancement within a chosen field. Similar findings are described in a study by Gagnon and Cocolas (1988).

Another group of studies examines the effects of various recruitment strategies (e.g., Jackson, 1985; Malaney, 1985, 1987b; Moore, 1984). These studies suggest that personal contact by faculty and alumni can have a positive influence on a student's interest in a particular program.

A relatively small number of studies examine the factors that influence student application and matriculation decisions. Within this group of studies, most are descriptive in nature and are often based on small samples of students in a single field of study (e.g., Czinkota, Johnston, and Jelly, 1980; Malaney, 1983; McClain, Vance, and Wood, 1984; Remus and Isa, 1983; Stolzenberg and Giarrusso, 1988; Terkla, 1988) or on special populations such as women or minorities (e.g., Yens, Benenson, and Stimmel, 1986). Some rely solely on data from institutional records (e.g., McClain, Vance, and Wood, 1984) or on surveys only of students who matriculated at the surveying institution (e.g., Malaney, 1984). There is only a handful of studies based on larger samples of students representing a diverse set of programs (e.g., Malaney, 1987a; Olson and King, 1985; Olson, 1992). Overall, few of these studies report results based on multivariate analysis.

The findings of these studies suggest that graduate student decisions are affected by some of the same factors that influence students in their selection of an undergraduate college - namely, the academic reputation of the institution, program quality and size, price/cost, financial aid, geographic location, contact with faculty, and a student's individual characteristics such as academic ability and achievement. Where graduate students appear to differ from undergraduates is the greater influence on graduate students of spouse, family, and/or work considerations.

In general, then, the existing literature is still very limited in its ability to provide a broad and comprehensive understanding of the college choice decisions of graduate students. Furthermore, there has not evolved at the graduate level working hypotheses or theories regarding the enrollment decision process.

Theory and research on adult development in the context of education is another relevant and very large literature base that can only be briefly referenced here. For purposes of this study, key theoretical concepts are derived from Chickering and Havighurst (1981) who suggest that students at different stages of life will have differing needs that influence their educational and career goals. In particular, this stream of literature suggests that students will 
be influenced by age-linked developmental tasks relating to individual psychosocial needs, interpersonal relationships of marriage and family life, career preparation and maintenance, and the assumption of social roles in a broader societal context. The applicability of adult development theory to graduate students has been tested in at least one study (Kuh and Thomas, 1983), which presents evidence that graduate students experience the age-linked developmental transitions described in the most noted adult development theories. Thus, this study hypothesizes that prospective graduate students begin selecting a graduate school at a particular stage of adult development that will vary across individuals depending on their age and other life circumstances, and that the effects of these developmental differences are felt directly or indirectly throughout the decision process.

\section{RESEARCH DESIGN AND METHODOLOGY}

This study is based on a 1986 survey of 2,834 students admitted to master's and doctoral programs at the University of Michigan. The sample is diverse in terms of the academic fields represented (approximately 140) and the students' personal characteristics and backgrounds. Data sources for the study included university admission records as well as a mailed survey instrument to which 38 percent $(1,068)$ of the sample responded. Survey respondents were found to be representative of nonrespondents based on gender, race, measures of academic ability, and field of study. Some response bias was noted in that students who were from within the State of Michigan, who were 30 years of age and older, and/or who were University of Michigan alumni were somewhat more likely to respond to the questionnaire than other students in the study. The largest response bias, however, was based on enrollment status. Not surprisingly, students who decided to enroll at the University of Michigan were more likely to participate in the survey than were students who chose to enroll elsewhere.

The survey instrument was a self-administered paper questionnaire that was mailed to students in mid-June of 1986. A follow-up reminder and questionnaire was also sent to the entire survey group. The instrument gathered detailed information on various aspects of the student's college choice process including which schools were considered, identification of the primary "alternate university" (for University of Michigan enrollees, the school they would have attended had they not chosen Michigan, and for nonenrollees, the school they planned to attend), campus visits, financial aid, student rankings of the importance of various college characteristics, and identification of the preferred school on those same characteristics. Regarding the latter two items, students were asked first to rate 31 institutional or program characteristics based on the degree of importance each factor played in their final enrollment decision. Students used the following four-point scale: $4=$ deciding factor, $3=$ important, 
$2=$ not too important, and $1=$ not considered. Students were then asked to indicate for each item if they preferred the University of Michigan on that characteristic, their alternate university, or if both schools were equally preferred.

The dependent variable in this study is the decision to enroll or not to enroll at the University of Michigan. A student's eventual enrollment status was determined by official university registration records as of the twelfth week of the Fall 1986 term.

Exploration and analysis of the data was carried out in three stages: (1) bivariate analyses to test which decision factors were associated with age, the primary indicator of life stage in this study; (2) bivariate analyses to test which decision factors were associated with the decision to enroll or not to enroll at Michigan; and (3) multivariate analyses to determine the primary dimensions of student decisions and their relative simultaneous effects on the final enrollment decision. Findings from the bivariate analyses are described in detail in Kallio (1993) and briefly summarized below. The primary purpose of this paper is to describe the methodology and results of the multivariate stage of analysis.

A key finding of bivariate analyses was that younger students under the age of 30 were more geographically mobile than older students and therefore considered a larger and more geographically dispersed set of institutions. Younger students also tended to place greater importance than did older students on social aspects of campus life and were more likely to be undecided about their specific career plans. In contrast, older students placed greater importance on spouse- and work-related considerations and were more likely to be pursuing graduate studies as a means of furthering a career track to which they were already committed.

Results of bivariate analyses also suggested that factors like the following were associated with the enrollment decision: age, residency status, indicators of a student's academic ability, alumni status, campus visits, financial aid, spouse job or education plans, the ability to continue working in a current job, and college characteristics such as program quality, geographic location, research opportunities, recruitment by faculty, social opportunities, quality of daily campus life, and cost.

\section{RESULTS FROM MULTIVARIATE ANALYSIS}

The intent of this analysis was to specify a multivariate model of the enrollment decision that provided a good fit for the sample overall while testing for any separate age-related or gender-related effects. The results of bivariate analyses were used to guide the development of the model.

Since many of the 62 variables representing ratings of importance and preferred school on particular decision factors were found to be significantly re- 
lated to age and/or enrollment status in bivariate analysis, a methodology was needed to reduce the number of variables to test in a multivariate model. To begin this data reduction effort, a principal axis factor analysis with a varimax rotation was carried out on the 31 variables representing the ratings of importance on the various decision factors. Table 1 presents the results of this factor analysis.

A four-factor solution was obtained using the criterion of eigenvalues greater than or equal to 1.0. The first factor obtained identified 12 items with a loading factor of 0.400 or higher. This factor is labeled "academic" since the items that load on it pertain largely to various aspects of the academic environment of the institution and to the student's program of study. The second factor obtained, "work," included three items relating to student desires to continue working in a current job, to pursue studies on a part-time basis, or to be eligible for an employer's tuition reimbursement program. The third factor is labeled "spouse" as it consists of two decision factors relating to a spouse's educational or job plans. The final factor obtained is labeled "social" since the three highest-loading items (loading factors 0.565 or more) largely pertain to the social environment of the campus and the program (i.e., quality of daily campus life, social/ cultural opportunities, and friendship opportunities). Although two other items had loading factors on this dimension slightly above 0.400 , they were not included in further analysis because there was such a large distance in the loading factors and a relatively weak conceptual link between them and the highest loading items.

\section{Scales Importance and Preference}

In order to test the influence of student perceptions and attitudes on the enrollment decision in multivariate analysis, it was necessary to develop scales that incorporate both the ratings of importance on items as well as the rating of the preferred school. Hence, the results of the factor analysis were used to build four scales representing the four decision dimensions identified in the analysis.

Both the literature on the college choice process and logic suggest that students are affected simultaneously by their perceptions of the importance of an item and the preferred school on it. One would assume that items of greatest importance and clear preference for one school or the other would influence students' final college choice decisions the most. It is much less likely that items of low importance or where both schools are equally preferred would have a strong effect on a student's final decision. Thus, scales representing the academic, work, spouse, and social dimensions of a decision were developed that capture both the importance and preference of the items on which these dimensions are defined. 
TABLE 1. Factor Analysis with a Varimax Rotation of the Ratings of Importance on Various Enrollment Decision Factors $(N=894)$

\begin{tabular}{|c|c|c|c|c|}
\hline \multirow[b]{2}{*}{ Decision Factor } & \multicolumn{4}{|c|}{ Factor Loadings } \\
\hline & $\begin{array}{c}\text { I } \\
\text { Academic }\end{array}$ & $\begin{array}{c}\text { II } \\
\text { Work }\end{array}$ & $\begin{array}{c}\text { III } \\
\text { Spouse }\end{array}$ & $\begin{array}{c}\text { IV } \\
\text { Social }\end{array}$ \\
\hline Institution's academic reputation & .414 & .108 & -.038 & .038 \\
\hline Diversity of course offerings & $\overline{.514}$ & -.014 & -.021 & .145 \\
\hline Value of a degree from this school & $\overline{.471}$ & -.006 & -.040 & .141 \\
\hline Geographic location of the institution & $-\overline{.065}$ & -.313 & -.007 & .274 \\
\hline Social/cultural opportunities & .083 & .008 & -.015 & .626 \\
\hline Library facilities \& collections & .435 & -.038 & .116 &.$\overline{332}$ \\
\hline Research and computer facilities & $\overline{.396}$ & .003 & -.002 & .208 \\
\hline Quality of day-to-day campus life & .184 & .141 & .001 & .640 \\
\hline Admissions process \& policies & .212 & -.068 & .136 & $\overline{.411}$ \\
\hline Sensitivity to minorities \& others & .181 & -.032 & .101 & .405 \\
\hline Size of the department & .421 & .122 & .122 & $\overline{.159}$ \\
\hline Particular field of study available &.$\overline{.461}$ & -.031 & .473 & .005 \\
\hline Reputation of department's faculty & .611 & .123 & .083 & .044 \\
\hline Quality of teaching & $\overline{.595}$ & .039 & .045 & .164 \\
\hline Research opportunities & $\overline{.418}$ & .128 & .137 & .059 \\
\hline Quality of students enrolled in program & $\overline{.421}$ & .157 & .110 & .309 \\
\hline Opportunities for friendships & $\overline{.208}$ & .078 & .022 & .565 \\
\hline Opportunity to teach & .206 & .239 & .295 & .208 \\
\hline Opportunity to work w/particular faculty & .414 & .153 & .319 & .097 \\
\hline Interest of faculty in recruiting me & $\overline{.252}$ & .216 & .328 & .097 \\
\hline Postgraduate job placement & .355 & .068 & .072 & .238 \\
\hline Program structure \& requirements & .424 & -.194 & .039 & .161 \\
\hline Length of time to degree & $\overline{.307}$ & -.235 & .043 & .152 \\
\hline Ability to pursue studies part-time & .029 & -.688 & .132 & .017 \\
\hline Job availability for spouse/partner & -.072 & -.122 & .632 & -.053 \\
\hline Spouse/partner educational plans & -.012 & -.090 & $\overline{.610}$ & .091 \\
\hline Availability of child care & -.022 & -.114 & $\overline{.367}$ & .056 \\
\hline Availability of university housing & .121 & .026 & .223 & .181 \\
\hline Recommendation of a mentor & .257 & .126 & .213 & .026 \\
\hline Ability to continue in current job & -.023 & -.757 & .076 & -.137 \\
\hline Employer tuition reimbursement & -.040 & -.544 & .022 & -.082 \\
\hline Eigenvalue & 4.659 & 1.82 & 1.206 & 1.096 \\
\hline$\%$ of common variance & 11.0 & 5.9 & 4.6 & 6.8 \\
\hline$\%$ of cumulative variance & 11.0 & 16.9 & 21.5 & 28.3 \\
\hline
\end{tabular}

Notes: Rotated loadings of 0.400 and greater are in boldface and underlined.

Ratings of importance were based on a four-point scale where $4=$ a deciding factor and 1 $=$ not considered. 
The first step in building these scales was to develop a scale of importance for each dimension based on the items identified in the factor analysis. The importance scale was calculated by adding together the rated importance for the relevant items for students who had an alternate college. The additive scale was then divided by the number of items included in it. Thus, the final version of each importance scale ranged from 1 to 4 where a 1 means that the student rated each item included in the scale as "not considered" and a 4 means that a student rated each item as "a deciding factor."

A scale of preference was then created for each of the four dimensions. Each preference scale was initially set equal to zero for all students who had an alternate college. The scale was then computed by adding one to it for each item on which Michigan was the preferred school and subtracting one each time the alternate was the preferred school. As a final step, the additive scale was then divided by the number of items included in it. Thus, each preference scale ranged from -1 to +1 where a -1 represents the alternate university having been preferred on every item in the scale and a +1 represents the University of Michigan having been preferred on every item.

The final step was to multiply the scale of importance times the scale of preference on each of the four dimensions-academic, work, spouse, and social. This resulted in four scales that ranged from -4 to +4 where a -4 represents a student who placed the highest level of importance on the items included in the scale and always preferred the alternate college on each, and a +4 represents a student who placed the highest level of importance and consistently preferred the Univcrsity of Michigan on the same items.

Since the influence of financial aid on the enrollment decision was raised in a set of questions separate from (but similar to) those in which the students rated the importance of various college characteristics and other decision factors, it was not included in the factor analysis. Therefore, a comparable scale of importance and preference was needed in order to represent this important decision dimension in the multivariate model. Following a methodology similar to that described above, a scale of importance and preference was developed for financial aid that ranged from -4 to +4 where -4 represents a deciding factor in which the alternate was preferred and +4 represents a deciding factor in which Michigan was preferred.

\section{Regression Model}

Ordinary least squares regression was used to test various combinations of variables representing the different components of the college choice decision process. Besides the five scales of importance and preference, other independent variables tested include age, gender, residency status, alumni status, and a 
series of interaction terms between the importance/preference scales and age and then gender. Thus, the final model that was tested is of the form:

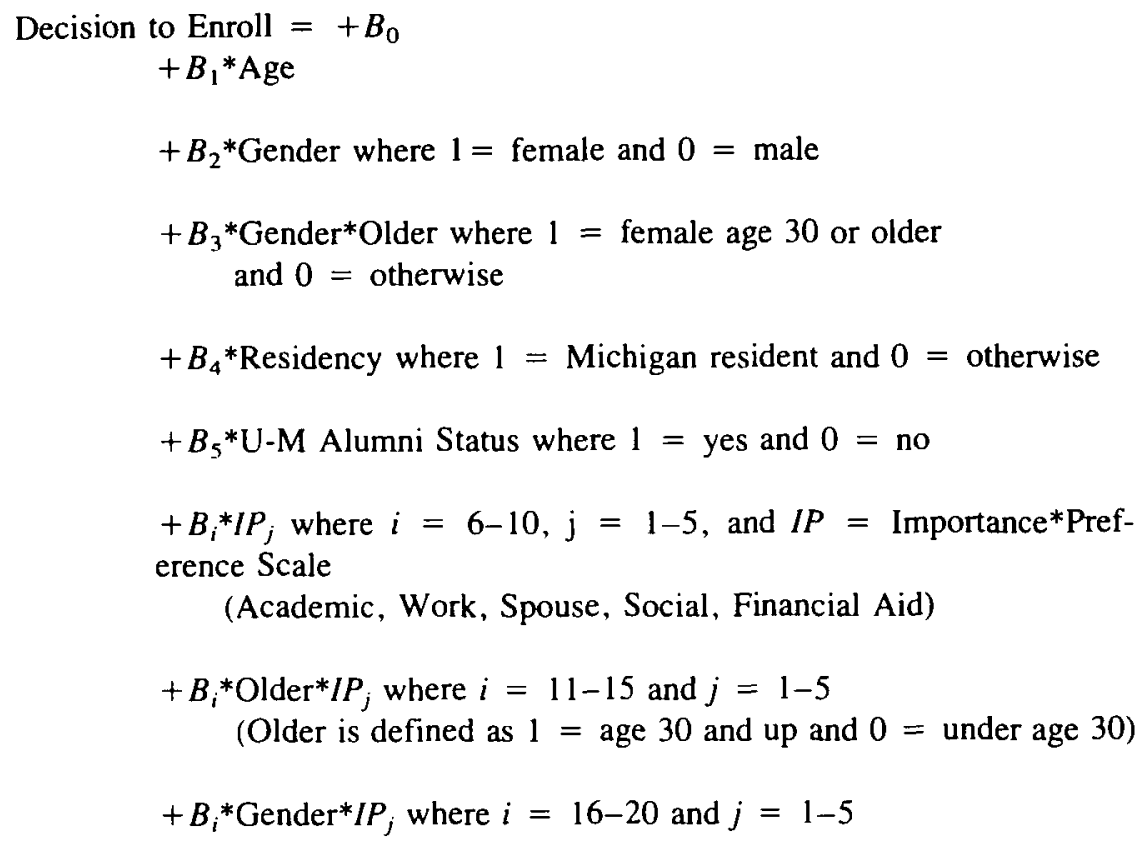

and

Decision to Enroll $=1$ if the student enrolled at Michigan and 0 otherwise

Table 2 presents the regression results for the specified model when the variables are entered simultaneously. This model provides a good fit to the data as evidenced in the relatively high $R^{2}$ statistic of 0.500 . These results were also replicated in logit analysis, a stronger statistical technique for models in which the dependent variable is dichotomous.

As Table 2 indicates, seven variables were significantly related to student decisions on whether or not to enroll at the University of Michigan. Not surprisingly, the results show that being a resident of the State of Michigan was associated with an increased likelihood of enrolling at the University of Michigan. The significance of the five scales of importance and preference (academic, work, financial, spouse, and social) also provide evidence that these were important dimensions along which student decisions were made. Because the five variables of importance and preference were scaled the same way, their 
TABLE 2. Regression of the Enrollment Decision on Personal Characteristics and Scales of Importance and Preference

\begin{tabular}{lcc}
\hline & Beta Coefficient & T-ratio \\
\cline { 2 - 3 } Constant & .286 & $2.684^{* *}$ \\
Age & .002 & .499 \\
Gender $(1=$ female, $0=$ male) & .023 & .801 \\
Gender $\times$. Older $(1=$ female age 30 and up, and & & \\
$0=$ otherwise) & -.031 & -.394 \\
Residency $(1=$ in-state resident, $0=$ outstate) & .123 & $3.261^{* * *}$ \\
U-M Alumnus/a Status $(1=$ Yes, $0=$ No) & -.009 & -.157 \\
Scales of Importance $\times$ Preference & & \\
Academic & .154 & $11.936^{* * * *}$ \\
Work & .141 & $3.320^{* * *}$ \\
Spouse & .058 & $2.930^{* *}$ \\
Social & .047 & $3.135^{* *}$ \\
Financial Aid & .059 & $8.114^{* * * *}$ \\
Interactions & & \\
Older $\times$ Academic & -.026 & -.084 \\
Older $\times$ Work & -.273 & $-4.250^{* * * *}$ \\
Older $\times$ Spouse & -.003 & -.086 \\
Older $\times$ Social & .012 & .286 \\
Older $\times$ Financial Aid & .007 & .423 \\
Gender $\times$ Academic & -.001 & -.066 \\
Gender $\times$ Work & .080 & 1.353 \\
Gender $\times$ Spouse & -.012 & -.451 \\
Gender $\times$ Social & -.027 & -1.149 \\
Gender $\times$ Financial Aid & .005 & .432 \\
\hline$N=$ & 695 & \\
$R^{2}$ & .500 & \\
$F$-statistic & 33.738 & \\
Signif. & $0 . * * * *$ & \\
\hline & & \\
\hline
\end{tabular}

${ }^{* *} p \leq 0.01,{ }^{* * *} p \leq 0.001,{ }^{* * * *} p \leq 0.0001$.

Note: The dependent variable is coded as follows: $1=$ Enrolled at Michigan, $0=$ Did not enroll at Michigan.

beta coefficients can be compared as to their relative effects on the enrollment decision. Using the beta coefficient as the yardstick, the academic scale (beta $=0.154$ ) had the largest effect on the enrollment decision, followed by the scales representing work $(0.141)$, financial aid $(0.059)$, spouse $(0.058)$, and social $(0.047)$ dimensions of the decision.

Only one interaction term representing the importance and preference on the work scale coupled with being older is significant in the model. Unfortunately, the negative sign on the beta coefficient $(-.273)$ is in the opposite direction 
from what one would expect (an increase in the work importance and preference scale of 1 point should be associated with an increased leaning toward the University of Michigan). It is not clear why this result is counter to expectation and to the results of the other significant variables. One probable contributing factor, however, is the small number of cases on which the results are based and that appear to reflect some instability in student responses. Among students age 30 and up, there were only 35 enrolled and 52 nonenrolled who were included in the regression analysis. A closer review of the work scale values for this group revealed a great deal of variance, suggesting that even though some older students indicated that work was important and that they preferred Michigan on that factor, other factors must have had overriding importance and preference and led to the decision not to enroll.

Some of the nonsignificant findings in the model are also worth noting, particularly the lack of significance associated with age and gender variables and their related interaction terms (with the exception of the older $\times$ work interaction already described). All else being equal, being female, older, or female and older did not increase one's probability of enrolling. This finding probably reflects the fact that the model controls for the relative importance of many of the factors that often distinguished the responses of older students and/or females in bivariate analysis.

In summary, the multivariate analysis suggests that graduate students, when selecting a graduate school to attend, base their decisions on at least six types of primary factors: residency status, characteristics of the academic environment of the institution and its programs, work-related concerns, spouse considerations, financial aid, and the social environment of campus life. These findings provide support for the two general hypotheses of this study. The components of the multivariate model support the first general hypothesis that the college choice decision of graduate students is a complex one, affected by a wide range of decision factors such as personal characteristics, other extemal influences such as spouses, and student perceptions, comparisons, and weightings of particular college and program characteristics. Furthermore, the significance of the work and spouse dimensions of the decision provides support for the hypothesis that student decisions are influenced by the effects of life stage and adult development.

\section{DISCUSSION}

The results of this study point to both similarities and differences between prospective graduate and undergraduate students in terms of the relative influence of factors affecting their selection of a college or university, assuming traditional-age students in both populations. What they appear to share in common is the strong role that residency plays in college choice decisions and the 
importance of academic environment factors such as the reputation and quality of the institution and its programs, course diversity, size of the institution/ department, and the like. The importance of financial aid is also a shared characteristic. Where they differ is how graduate students are influenced by work and spouse considerations. It would appear that social factors, while still of importance to graduate students, are of a lesser concern than tends to be the case for undergraduates. The significance of the social scale in the regression results of this study probably reflects the fact that the age distribution of the sample of graduate students was heavily skewed toward younger individuals (mean age of 25). The same model run on another sample of students with greater representation by those over the age of $30 \mathrm{might}$ well produce different results in terms of the significance and relative influence of this scale.

In general these findings are consistent with some of the typical differences between graduate students and undergraduates in terms of life stage. The importance of spouse and work-related considerations among graduate students reflect "early adulthood" (age range 23-35) tasks identified in the adult development literature such as deciding on a life partner, starting a family and managing a home, starting and developing an occupation, etc. The influence of a spouse/partner has also been found to be significant in other studies of graduate students (e.g., Olson and King, 1985). Research on undergraduates, on the other hand, has established that parents have substantial influence early in the process through the setting of decision boundaries-particularly those related to finances, geographic location, and school quality-but that students make the final college choice decision. Again, this is consistent with adult development theory, which says that one of the primary development tasks of "late adolescence and youth" (age range 16-23) is becoming independent of one's parents. A difference between the effect of parents on undergraduate decisions versus the effect of spouses on graduate student decisions is the stage of the process where the influence is exercised. The influence of parents is felt primarily in the early stages of the process when students are deciding which schools to apply to, whereas the influence of spouses appears to carry through to the final choice decision. Thus, undergraduates and graduate students are similar in that a primary familial relationship can influence the decision process; they appear to differ, however, on when and how that significant person exerts influence.

The significance of residency status in the regression results, while perhaps not surprising, is somewhat difficult to interpret because it can reflect any number of underlying and interrelated decision factors. For example, it can reflect concerns about cost because of the tuition differentials associated with in-state versus out-of-state status. It can also reflect, however, other important considerations such as proximity of the institution to where a student lives and works, or because of proximity, greater familiarity with an institution, its programs, and faculty. 
In summary, the findings described in this paper are largely consistent with those of other studies on graduate student college choice decisions. Furthermore, they also provide evidence to support the hypothesis that the decision process for selecting a graduate school is a complex one involving the characteristics and actions of both the students and the institutions they are considering. The results of this study also suggest that the effects of life stage development can significantly influence student behavior in the decision process.

Since the findings of this study are based on a sample of graduate students admitted to a major research university, the implications that can be drawn from the results are applicable primarily to students and administrators at similar institutions. The recommendations that follow will generally pertain to policies and practices that institutions and departments might consider instituting in order to improve the effectiveness of their efforts to recruit students to their graduate programs. For example, recognizing life stage-related differences in the pools of potential applicants and admitted students and understanding how those differences affect the relative weights students give to various decision factors can be used by institutions and departments to develop new recruitment strategies and techniques.

It would appear from this study that general recruitment strategies should first and foremost take into account student concerns about the quality of the institution and of the particular department or program. Informational materials and other communications with students such as face-to-face contact should also address other aspects of the academic environment that students consider such as the diversity of course offerings, size of the department, library facilities and collections, and research and other opportunities to work with particular faculty. It is also important to address perceptions of the social aspects of campus life. Perhaps the most effective way of doing this is to facilitate interaction between potential students and those who are currently enrolled in the department's programs.

The need and desire of students to factor into their decisions the education and career plans of a spouse or partner is a major finding of this study. Although this probably is not a "new" concern for graduate students, it is one that has largely been downplayed in institutional policies and practices. The most common institutional practice is to let students fend for themselves in solving the dilemmas that can arise in this area. Attention paid to the education and work plans of spouses, however, could pay dividends for departments actively recruiting particular individuals. Just as major research universities today often provide job search and other types of services to the spouses of faculty who are being heavily recruited, it might be feasible to consider offering similar services to graduate students as well. For a variety of practical reasons, such services would probably have to be offered through or coordinated by a central administrative office located in the graduate school or in the student services 
area. Services provided could include job search assistance, information on educational opportunities, information on the availability of child-care services, and the like.

Finally, the importance of financial aid considerations suggests that greater investments in any or all aspects of offering assistance might improve an institution or department's ability to recruit students.

The implications of this study for further research are many but can be reduced to a simple plea for more research on graduate students, period. Because of the general lack of research on graduate students, especially theory-driven studies of their college choice decisions, there is a great need for research on virtually all aspects of the decision process. Both descriptive and theoretical studies have much to contribute to a better understanding of the factors that influence decisions, their relative weightings, and the stages of the decision process.

One area in particular that merits further study is the effect of cost and financial aid on decisions. Much of the research findings in the existing literature are inconsistent and often contradictory. There are many reasons for these seeming discrepancies, including the complicated nature of financial aid funding and methodological problems related to the use of appropriate measures and accurate data collection procedures.

It is also important that future studies be based on larger samples of students drawn from a broad range of programs and institutions - and that study results be translated into a published body of literature.

In conclusion, this study presents the results of a multivariate analysis of the factors influencing the college choice decisions of a group of admitted graduate students at one of the nation's major research universities. The results of the study suggest that graduate students, when selecting a graduate school to attend, base their decisions on at least six types of primary factors: residency status, characteristics of the academic environment of the institution and its programs, work-related concerns, spouse considerations, financial aid, and the social environment of campus life. Of the six factors, residency, academic, and work considerations appear to have the greatest influence on student decisions.

\section{REFERENCES}

Baird, L. L. (1976). Who goes to graduate school and how they get there. In J. Katz and R. T. Hartnett (eds.), Scholars in the Making: The Development of Graduate and Professional Students (pp. 19-48). Cambridge, MA: Ballinger.

Chickering, A. W., and R. J. Havighurst (1981). The life cycle. In A. W. Chickering and Associates, The Modern American College (pp. 16-50). San Francisco, CA: Jossey-Bass.

Czinkota, M. R., W. J. Johnston, and E. C. Jelly (1980). Medicine and marketing: The case of graduate medical education. Journal of Medical Education 55(11): 906-911. 
Ethington, C. A., and J. C. Smart (1986). Persistence to graduate education. Research in Higher Education 24(3): 287-303.

Gagnon, J. P., and G. H. Cocolas (1988). Understanding what motivates someone to pursue pharmacy graduate education. American Journal of Pharmaceutical Education 52(1): $10-15$.

Garet, M. S., P. Butler-Nalin, and S. Bassage (1982). Graduate and Professional Education: A Review of Recent Trends. Washington, DC: National Commission on Student Financial Assistance.

Goldberg, F., and R. Koenigsknecht (1985). The Highest Achievers: Post-baccalaureate Enrollment of Four Classes Between 1956 and 1981. Cambridge, MA: Consortium of Financing Higher Education.

Hossler, D., J. Braxton, and G. Coopersmith (1989). Understanding Student College Choice. In J. C. Smart (ed.), Higher Education: Handbook of Theory and Research, Volume V (pp. 231-288). New York: Agathon Press.

Hossler, D. R., and K. S. Gallagher (1987). Studying student college choice. A threephase model and the implications for policy-makers. College and University 62(3): 207-221.

Jackson, T. J. (1985). Bolstering graduate school enrollments through effective use of alumni. College and University 60(3): 210-218.

Kallio, R. E. (1993). The college choice decision of graduate students. Doctoral dissertation, The University of Michigan, Ann Artor, MI (University Microfilms No. 9332097).

Kotler, P. (1976). Applying marketing theory to college admissions. In College Entrance Examination Board (ed.), A Role for Marketing in College Admissions (pp. 54-72). New York: College Entrance Examination Board.

Kuh, G. D., and M. L. Thomas (1983). The use of adult development theory with graduate students. Journal of College Student Personnel 24(1): 12-19.

Kuh, G. D., J. P. Bean, R. K. Bradley, M. D. Coomes, and D. E. Hunter (1983). Changes in research on college students published in selected journals between 1969 and 1983. The Review of Higher Education 9(2): 177-192.

Litten, L. H., D. Sullivan, and D. L. Brodigan (1983). Applying Market Research in College Admissions. New York: College Entrance Examination Board.

Malaney, G. D. (1983). Graduate student recruitment in professional public administration programs: A low-cost method of projecting potential student markets. College and University 58(Spring): 260-269.

Malaney, G. D. (1984). An analysis of financial aid in the recruitment of graduate students at The Ohio State University. Journal of Student Financial Aid 14(1): 11-19.

Malaney, G. D. (1985). An organizational perspective of graduate student recruitment: A resource dependence approach. The Review of Higher Education 8(4): 375-386.

Malancy, G. D. (1987a). Why students pursue graduate education, how they find out about a program, and why they apply to a specific school. College and University 62(3): 247-258.

Malaney, G. D. (1987b). Efforts to recruit graduate students: An analysis of departmental recruiting practices. College and University 62(2): 126-136.

Malaney. G. D. (1988). Graduate education as an area of research in the field of higher education. In J. C. Smart (ed.), Higher Education: Handbook of Theory and Research. Volume IV (pp. 397-454). New York: Agathon Press.

Malaney, G. D., and P. D. Isaac (1988). The immediate post-baccalaureate educational plans of outstanding undergraduates. College and University 63(2): 148-161.

McClain, D., B. Vance, and E. Wood (1984). Understanding and predicting the yield in the MBA admissions process. Research in Higher Education 20(1): 55-76. 
Moore, T. E. (1984). Source credibility and attribution theory: Effects on graduate student recruiting. Dissertation Abstracts International 44(8): 2379A.

National Center for Education Statistics (1989). Projections of Education Statistics to 2000 (NCES 89-648). Washington, DC: U.S. Department of Education, National Center for Education Statistics.

Olson, C. (1992). Is your institution user-friendly? Essential elements of successful graduate student recruitment. College and University 67(3): 203-214.

Olson, C., and M. A. King (1985). A preliminary analysis of the decision process of graduate students in college choice. College and University 60(4): 304-315.

Paulsen, M. B. (1990). College Choice: Understanding Student Enrollment Behavior (ASHE-ERIC Higher Education Report No. 6). Washington, DC: The George Washington University, School of Education and Human Development.

Remus, W., and D. Isa (1983). Predicting actual university enrollments. College Student Journal 17(2): 137-140.

Stolzenberg, R. M., and R. Giarrusso (1988). First Results from the GMAC's New Matriculants Survey: School Selection by Students (GMAC Occasional Papers). Princeton, NJ: Graduate Management Admission Council.

Terkla, D. G. (1988). Beyond the baccalaureate: Using admissions research at the graduate professional school level. Paper presented at the Annual Forum of the Association for Institutional Research, Phoenix, AZ.

Yens, D. P., T. F. Benenson, and B. Stimmel (1986). Recruitment of underrepresented student groups: A controlled study. Journal of Higher Education 57(1): 44-57. 